\title{
Uso de indicadores na gestão dos resíduos sólidos urbanos: parte II - uma proposta metodológica de construção e análise para municípios e regiões: aplicação do modelo
}

\author{
Use of indicators in urban solid waste management: \\ a methodological proposal of construction and \\ analysis for cities and regions: application of the model
}

Suellen Silva Pereira1*, Rosires Catão Curi², Wilson Fadlo Curi²

\begin{abstract}
RESUMO
O presente trabalho teve por objetivo avaliar a gestão dos resíduos sólidos urbanos por meio da aplicação do modelo de gestão dos resíduos sólidos urbanos sustentável (MGRSUS) desenvolvido e aplicado em municípios que compõem a Região Metropolitana de Campina Grande (RMCG). O referido modelo é composto de 46 indicadores, 15 categorias de análise e quatro dimensões e estruturado por dados primários e secundários. Para a obtenção dos dados, foram realizadas entrevistas semiestruturadas e visitação in loco, além do levantamento bibliográfico e documental. Com base nos dados, verificou-se que os municípios de menor porte apresentam maiores problemas na gestão dos resíduos, o que pode estar relacionado ao fato de não possuírem uma equipe técnica para a execução dos serviços, o que reflete diretamente na qualidade ambiental urbana. Desse modo, o MGRSUS foi considerado satisfatório para os fins aos quais se propôs, haja vista foi possível traçar um panorama da gestão de cada município, possibilitando o direcionamento de ações específicas para cada lacuna identificada.
\end{abstract}

Palavras-chave: modelo de gestão de resíduos sólidos urbanos; indicadores, sustentabilidade

\begin{abstract}
This study aimed to evaluate the management of urban solid waste through the application of the management model of sustainable urban solid waste (MGRSUS) developed and implemented in municipalities that make up the metropolitan area of Campina Grande. The model is composed of 46 indicators, 15 categories of analysis and four dimensions and structured by primary and secondary data. In order to obtain those data, semi-structured interviews and on-site visits occurred, in addition to literature and documentary search. Based on those data, it was found out that the smaller municipalities have greater problems in waste management, which can be related to the fact they do not have a technical team to deliver the services, reflecting directly over the urban environmental quality. So, the MGRSUS was considered satisfactory for the purposes for which it is proposed, taking into account it was possible to give an overview of the management of each municipality, enabling the targeting of specific actions for each identified gap.
\end{abstract}

Keywords: urban solid waste management model; indicators; sustainability.

\section{INTRODUÇÃO}

Um dos grandes problemas ambientais urbanos da atualidade é a crescente geração de resíduos - no caso do presente estudo, a dos resíduos sólidos urbanos (RSU) -, que acaba por sofrer influência direta do crescimento populacional, do processo de industrialização e do aumento do consumo (AMORIN, 1996; JACOBI \& BESEN, 2006; MELO et al., 2009; SILVA et al., 2014). Para Motta (2006), o processo de urbanização em todo o mundo incrementa a geração per capita de RSU, principalmente em regiões metropolitanas, nas quais a geração de resíduos inorgânicos tende a apresentar crescimento considerável quando comparada às demais localidades.

Já há 13 anos, Moraes (2003) afirmou que o modelo de gestão de RSU predominante no Brasil, baseado na coleta e no afastamento dos

'Universidade Federal de Campina Grande (UFCG) - Campina Grande (PB), Brasil. ${ }^{2}$ Professor(a) da UFCG - Campina Grande (PB), Brasil.

*Autor correspondente: suellenssp@hotmail.com

Recebido: 05/05/2016 - Aceito: 06/03/2017 - Reg. ABES: 163503 
resíduos gerados e, quando muito, na sua disposição adequada, constituía soluções geralmente isoladas e estanques, mostrando-se inadequado e necessitando de mudanças.

No ano de 2010, foi instituída a Política Nacional de Resíduos Sólidos (PNRS), a Lei no 12.305/2010, que dispõe sobre os princípios, objetivos e instrumentos, bem como sobre as diretrizes relativas à gestão integrada e ao gerenciamento de resíduos sólidos, incluindos os perigosos; às responsabilidades dos geradores e do poder público; e aos instrumentos econômicos aplicáveis.Atualmente, ela é o principal instrumento regulador da problemática dos RSU, que se torna, a cada dia, mais alarmante (BRASIL, 2010).

Pelo exposto, pode-se dizer que a gestão integrada e sustentável dos RSU é, em essência, uma abordagem sistêmica, visto que termina por envolver diversas etapas para o seu efetivo equacionamento, como, por exemplo, a geração e a maximização de seu reaproveitamento, acondicionamento, coleta, transporte, transferência, tratamento e disposição final.

Não obstante essa complexidade, a problemática dos RSU deve envolver, para o seu equacionamento, uma equipe de profissionais interdisciplinares, buscando atender às diversas etapas que compõem o processo de gestão integrada dos RSU (PGIRSU), cabendo aos gestores municipais, por meio de suas secretarias, o desenvolvimento de campanhas educativas que mobilizem toda a sociedade, organizada ou não, no engajamento que a temática em questão requer.

Ainda sobre a PNRS, tem-se como mecanismo para a análise de desempenho operacional e ambiental, dos serviços públicos de limpeza urbana e de manejo dos RSU o seu artigo $19^{\circ}$, parágrafo VI, que inclui os indicadores como conteúdo mínimo nos planos municipais de gestão integrada. Assim, os indicadores de sustentabilidade aplicados na gestão dos RSU (GRSU) tornam-se instrumentos importantes para que os gestores públicos e a população possam avaliar e monitorar a sustentabilidade nas suas múltiplas dimensões e planejar estratégias da gestão, favorecendo a melhoria na qualidade de vida da comunidade.

Com base em Polaz e Teixeira (2007), o processo de construção, uso e avaliação dos chamados indicadores de sustentabilidade contribui para a denúncia de realidades insustentáveis. Essa ferramenta é útil para as etapas de concepção, planejamento, monitoramento e avaliação de políticas públicas em diversas áreas, inclusive naquelas voltadas para a gestão dos RSU.

Tal preocupação vem norteando trabalhos de diversas naturezas, na esfera institucional/pública, por meio de órgãos ligados ao governo federal (Sistema Nacional de Indicadores de Saneamento - SNIS; Indicadores de Desenvolvimento Sustentável do Instituto Brasileiro de Geografia e Estatística - IDS/IBGE, Pesquisa Nacional de Saneamento Básico do IBGE - PNSB/IBGE), privada (Panorama dos Resíduos Sólidos no Brasil da Associação Brasileira de Empresas de Limpeza Pública e Resíduos Especiais - ABRELPE), e/ou em pesquisas científicas de instituições de ensino superior (IES) (BAASCH, 1995; SIENA, 2002; MILANEZ, 2002; POLAZ, 2009; ANDRADE \& SILVA, 2009; UGALDE, 2010; MELO et al., 2009; SILVA \& BASSI, 2012; RAMOS, 2013; SILVA et al., 2014; CASTRO et al., 2015, SILVA el al., 2015, entre outras), todos engajados na busca de alternativas que viabilizem a gestão adequada dos RSU e, por conseguinte, a melhoria da qualidade ambiental e de vida da população local.

Nessa perspectiva, a análise dos modelos de gestão de RSU adotados pelas gestões públicas municipais, bem como a sua adequação aos preceitos da sustentabilidade por meio do uso de indicadores, torna-se extremanente necessária para que se possa diagnosticar a real situação dos RSU, como forma de traçar estratégias com base nas fragilidades identificadas em cada situação investigada.

Assim sendo, o presente artigo teve por objetivos propor e aplicar um modelo sistêmico e estruturado com base em indicadores e índices para avaliar a gestão dos RSU. O modelo é aplicável tanto para municípios quanto para regiões, sendo o objeto de análise, aqui, a Região Metropolitana de Campina Grande (RMCG), de maneira que se pudesse obter um panorama geral da região, com enfoque nas dimensões socioeconômicos, ambientais e técnico-operacionais, viabilizando e direcionando a tomada de decisão e investimentos no setor como forma de buscar a eficiência, a eficácia e a sustentabilidade da gestão dos RSU.

\section{ESTADO DA ARTE}

A PNRS, Lei no 12.305/2012 (BRASIL, 2010), estabeleceu como prazo final para o encerramento dos lixões o mês de agosto de 2014. Cabe informar que o governo federal, em decorrência do grande número de municípios que não conseguiram cumprir a meta estabelecida, estendeu o prazo para essa transição dos lixões para aterros sanitários. Levando em consideração o porte do município, sendo que capitais e municípios integrantes de regiões metropolitanas (RM) ou de regiões integradas de desenvolvimento (RIDE) têm até 31 de julho de 2018 para acabar com as atividades de lixão; municípios com população superior a 100 mil habitantes, até 31 de julho de 2019; municípios com população entre 50 e $100 \mathrm{mil}$ habitantes, até 31 de julho de 2020 e municípios com população inferior a 50 mil habitantes, até 31 de julho de 2021. Logo, ficou determinado o mês de julho de 2021 como prazo final para o encerramento dos lixões. Levantamento da Confederação Nacional dos Municípios (CNM) revelou que pouco mais de $9 \%$ dos municípios cumpriram a primeira etapa do processo firmado pela PNRS, a elaboração do plano municipal de gestão integrada de RSU (GIRSU), cujo prazo venceu em 2 de agosto de 2012 (JORNAL DO BRASIL, 2014), tendo sido também prorrogado.

De acordo com Gomes e Andrade (2011), cerca de 50 municípios paraibanos enfrentam processo judicial por disporem os RSU em locais irregulares. Em alguns casos, a seccional Paraíba do Instituto Brasileiro do Meio Ambiente e dos Recursos Renováveis (IBAMA) ajuizou ação 
civil pública e, em outros, foram aplicadas multas pelo depósito de resíduos a céu aberto.

Outro indicador bastante relevante para a análise da gestão dos RSU é a cobertura da coleta regular, à qual a maioria dos gestores públicos se propõe a atender, principalmente quando considerado o perímetro urbano do município. A ampliação do serviço de coleta dos RSU vem apresentando avanços ao longo dos anos, chegando a 90,7\% (71.260.045 toneladas), o que indica que o Brasil caminha, ao menos, para universalizar esses serviços (ABRELPE, 2014).

No que se refere à frequência da coleta dos resíduos, Monteiro (2001) ressalta que a frequência mínima de coleta admissível em um país de clima quente como o Brasil é de três vezes por semana. Para Guerra (2011), uma maneira de avaliar a qualidade e eficiência do manejo dos RSU é a análise dos dados da frequência da coleta domiciliar e do tratamento dado aos resíduos no município, o que reforça a importância desse indicador.

Sobre a normalização dos serviços de transporte terrestre de resíduos, cabe destacar a Norma Brasileira (NBR) 13211 (ABNT, 2003), que especifica os requisitos básicos para o transporte dos resíduos, de modo a evitar danos ao meio ambiente e a proteger a saúde pública. A norma leva em conta os seguintes itens:

- o estado de conservação do equipamento deve ser tal que, durante o transporte, não permita vazamento ou derramamento do resíduo;

- o resíduo, durante o transporte, deve estar protegido das intempéries, assim como devidamente acondicionado, para evitar o seu espalhamento na via pública ou via férrea.
De acordo com Dantas (2013), do ponto vista econômico e ambiental os veículos de carroceria aberta são inviáveis, pois, como não há compactação, o volume de resíduo transportado é menor que nos caminhões compactadores, sendo necessárias mais idas ao local de disposição final para depositar o resíduo coletado. Desse modo, foram considerados como adequados os municípios que apresentaram caminhão coletor, visto que os demais veículos não estão em conformidade com a NBR 13221/2003.

No que tange à utilização de equipamentos de proteção individual (EPIs), Dantas (2008) ressalta a importãncia de um controle na utilização desses equipamentos, porque, como já dito, o trabalho com resíduos é insalubre. Portanto, os gestores públicos devem prover condições mínimas para os trabalhadores envolvidos nas atividades de gerenciamento dos RSU.

\section{MATERIAIS E MÉTODOS}

\section{Localização da área de estudo}

A região estudada é composta de 19 municípios, cuja população é de 606.047 habitantes, de acordo com o Censo Demográfico de 2010 (IBGE, 2010a), distribuídos em 4.739,72 km², o que corresponde à densidade demográfica de 127,86 habitantes $/ \mathrm{km}^{2}$. Apresenta-se, na Figura 1, a localização da RMCG no contexto do estado da Paraíba, com destaque para os municípios que integraram a amostra da presente pesquisa.

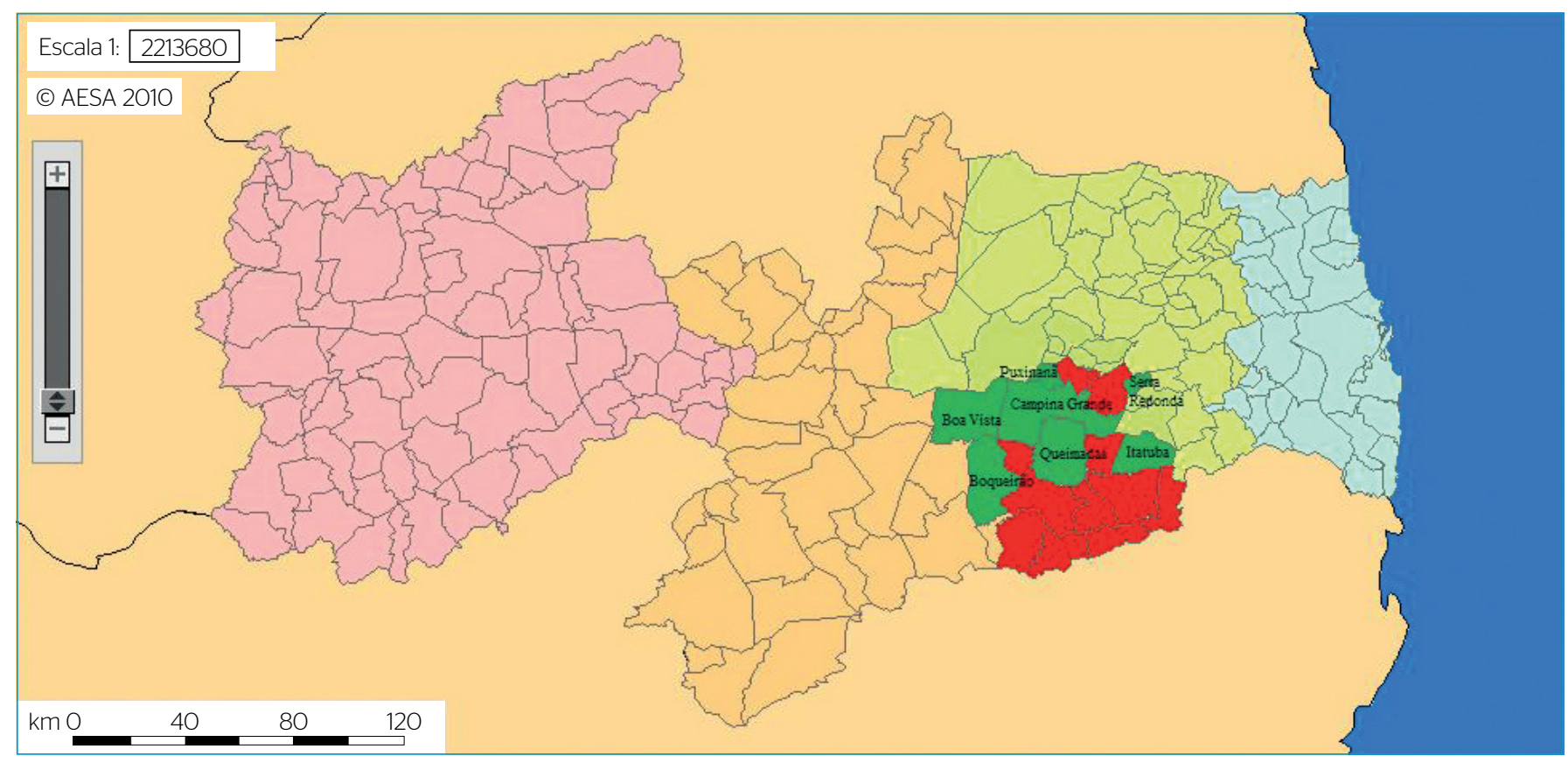

Fonte: adaptado de Paraíba (2012)

Figura 1 - Municípios que fazem parte da Região Metropolitana de Campina Grande (RMCG), em vermelho, bem como os municípios que compõem a amostra da pesquisa (em verde). 


\section{Universo amostral}

Tendo em vista que o objeto de estudo desta pesquisa foram os RSU, que têm maior representatividade nos municípios que possuem maior concentração da população dentro do perímetro urbano, foram elencados, para a análise da gestão, os municípios com maior representatividade de população urbana: Boa Vista, Boqueirão, Campina Grande, Itatuba, Queimadas e Serra Redonda.

Afora os municípios considerados urbanos, foi acrescentado à amostra Puxinanã, porque, apesar de possuir apenas 32,63\% da população no perímetro urbano, apresenta em seu território um aterro sanitário para disposição final dos RSU construído de modo a atender às cidades de Campina Grande, Puxinanã e Montadas, além de empresas privadas, fazendo-se importante o diagnóstico da supracitada localidade.

Nesses termos, a amostra total foi composta de 36,84\% da RMCG, totalizando sete municípios. Em termos populacionais, ela abrangia 79,13\%. Levando em consideração a concentração dessa população na área urbana do município, totalizou-se $90,30 \%$ da população, ficando garantida, por conseguinte, a representatividade da amostra selecionada.

\section{Instrumentos de coleta e análise dos dados da pesquisa}

A organização dos indicadores que compuseram o modelo proposto neste trabalho buscou estruturar as informações de modo que fosse possível levantar o maior número de dados em fontes secundárias, na tentativa de dotar o modelo de mais objetividade e confiabilidade, uma vez que a gestão municipal, por vezes, não possui informações suficientes para a realização da avaliação da GRSU de forma segura e confiável, fato que foi possível constatar in loco.

Desse modo, levando em consideração a dificuldade de levantamento de algumas informações em relação aos municípios pesquisados, procuraram-se informações em boletins oficiais do governo (federal ou estadual). Para tanto, algumas bases de dados foram consultadas:

- Pesquisa Nacional de Saneamento Básico - PNSB (IBGE, 2010b);

- censo demográfico (IBGE, 2010a);

- Pesquisa Nacional de Amostra por Domicílio (PNAD) (IBGE, 2010c);

- Atlas de Saneamento Básico (IBGE, 2011);

- Sistema Nacional de Informações sobre Saneamento - SNIS (BRASIL, 2012b);

- Banco de Dados do Sistema Único de Saúde - DATASUS (BRASIL, 2009);

- Portal da Cidadania do Tribunal de Contas do Estado da Paraíba (PARAÍBA, 2013).

Afora o levantamento de informações secundárias em base de dados, foram utilizados, para a coleta das informações primárias durante a pesquisa de campo, os seguintes instrumentos metodológicos:
- observação: foi o ponto inicial desta pesquisa, sendo possível, ao pesquisador, por meio deste instrumento, conhecer uma nova realidade, viabilizando, desse modo, mais interação com a problemática em estudo;

- entrevistas: o contato com o representante de cada pasta, por meio de ligações telefônicas, ocorreu quando as questões inerentes às ações desenvolvidas pelas supracitadas secretarias não foram consideradas suficientemente claras pelo setor responsável pela gestão dos RSU. Alguns contatos também foram realizados presencialmente, em visita previamente agendada com o(a) secretário(a).

Para a análise dos dados quantitativos, fez-se uso de técnicas estatísticas para sua interpretação, como método estatístico simples e cálculo médio. Os resultados foram organizados em gráficos de acordo com categorias, para a melhor visualização e compreensão. Os dados qualitativos foram avaliados por meio da análise de conteúdo (BARDIN, 1979), verificando as características sintáticas e semânticas do corpus do texto.

\section{RESULTADOS E DISCUSSÃO}

Os resultados serão apresentados de forma conjunta com as discussões, por meio de uma análise comparativa entre os municípios, considerando os dados obtidos pelos indicadores selecionados para compor o modelo, sendo esses apresentados segundo as respectivas dimensões. Para uma melhor visualização dos dados, o Anexo 1, apresentado ao final do artigo, traz uma síntese dos indicadores ora investigados.

\section{Análise comparativa dos municípios da Região Metropolitana de Campina Grande}

\section{Dimensão ambiental}

Esta dimensão visou avaliar aspectos inerentes aos impactos dos RSU sobre o meio ambiente. Dessa forma, um dos indicadores que podem ser destacados é a quantidade de RSU per capita. O município de Serra Redonda foi o que apresentou a maior geração per capita (1,6 kg/habitante/dia), seguido por Puxinanã (1,4 kg/habitante/dia); Campina Grande (1,23 kg/habitante/dia); Boa Vista e Itatuba, ambos com 1,2 kg/habitantedia; Boqueirão (0,832 kg/habitante/dia); e, por fim, com a menor geração, Queimadas $(0,764 \mathrm{~kg} /$ habitante/dia). Nesse caso, para efeito de cálculo, considera-se como fator positivo para a gestão a menor geração de RSU per capita.

Ressalta-se que para o cálculo dos dados referentes às cidades de Boa Vista e Itatuba, fez-se uso da média de geração per capita para a Região Nordeste, levando em conta a PNSB 2008. Essa medida deu-se, primeiramente, em virtude de Boa Vista não dispor de nenhuma informação referente ao quantitativo de resíduos coletados e, no caso de Itatuba, pelo fato de os dados fornecidos pelos gestores municipais 
estarem muito acima da média, o que pode caracterizar a junção de outros resíduos na composição dos RSU, como, por exemplo, os resíduos de construção e demolição (RCD).

Sobre os indicadores referentes à categoria coleta seletiva e triagem, informa-se que nenhum dos municípios pesquisados possuía programas institucionalizados que realizassem esses serviços. É possível identificar algumas iniciativas, a exemplo da cidade de Campina Grande, mas que estavam relacionadas a ações desenvolvidas por IES, que motivaram a organização de catadores de materiais recicláveis em cooperativas e associações.

A inexistência de dados favoráveis a respeito da categoria coleta seletiva e triagem não pode ser tida como um fato isolado, específico da região estudada, visto que, quando esses serviços existem, ainda são, em sua maioria, operados com ineficiência, comprometendo, por conseguinte, a sustentabilidade do programa.

No que se refere às formas de disposição final dos RSU coletados na região estudada, esta foi considerada ruim, pois cinco municípios (Boa Vista, Boqueirão, Itatuba, Queimadas e Serra Redonda) dos sete pesquisados estavam dispondo seus resíduos em vazadouros a céu aberto, os lixões, o que é compreendido, em conformidade com a avaliação da GRSU, como um ponto fraco, principalmente por conta da legislação vigente.

Apenas Campina Grande e Puxinanã, à época em que a pesquisa foi realizada, estavam destinando seus resíduos para um aterro sanitário, cuja instalação fica no próprio município de Puxinanã. Para esse item, foi considerado como positivo o município que realizava a disposição conforme o recomendado pela Lei $n^{\circ} 12.305 / 2012$, ou seja, no aterro sanitário.

O último indicador refere-se à recuperação de áreas de lixões. Verificou-se, em pesquisa de campo, que nenhum município promovia, ou estava promovendo, ações desse tipo, e tinham-se, em alguns casos, informações sobre a existência de projetos para o oferecimento de tais atividades, mas sem previsão de quando seriam colocados em prática.

\section{Dimensão social}

Para fins de análise, a dimensão em foco buscou informações referentes aos impactos dos resíduos no que diz respeito à ausência de uma adequada gestão dos RSU. Desse modo, verificou-se com base nas informações disponibilizadas pelos gestores municipais consultados que, afora o município de Itatuba, que declarou que 90\% da fração da população urbana era atendida pela coleta de resíduos, todos os demais informaram que a população urbana era atendida pela prestação desse serviço em sua totalidade. No que concerne à taxa de urbanização da população atendida pela coleta de resíduos, foi possível constatar oscilação desses percentuais. A Figura 2 apresenta mais informações acerca dos municípios pesquisados.

Tendo como base os numéros apresentados na Figura 2, vê-se que Campina Grande se destaca, entre os demais municípios, com uma taxa de urbanização da população atendida de 95\%; em seguida, aparece Boqueirão, com 71\%; e os demais oscilam entre 48 e 54\%.

Para esse indicador, cabe ressaltar que, apesar de praticamente todos os municípios terem declarado que $100 \%$ dos domicílios na zona urbana recebiam o serviço de coleta de RSU (com exceção de Itatuba, com 90\%), foi possível observar algumas taxas de urbanização um pouco baixas, o que, nesse caso específico, estava diretamente relacionado à urbanização da cidade. No caso de Puxinanã, por exemplo, que possuía maior concentração populacional na zona rural, era perceptível a baixa representatividade do percentual, o que se estendia aos demais municípios pesquisados.

Sobre a existência de catadores de materiais recicláveis, todos os gestores afirmaram ter conhecimento da presença deles, estando a maioria presente nas ruas e/ou nos lixões das cidades. Mesmo sabendo que uma parcela da população sobrevivia da atividade de coleta de materiais recicláveis, não se pôde identificar nenhuma ação por parte do poder público municipal no sentido de integrar esses trabalhadores em programas de inclusão social, os quais perpassavam pela criação e organização de cooperativas ou associações.

Desse modo, quando analisada a questão da formalização dessa categoria de trabalho, observou-se que apenas a cidade de Campina Grande apresentava cooperativas e associações, com o total de 47 catadores formais. Sobre o processo de formalização da categoria, registra-se que alguns municípios (Boqueirão e Queimadas) ressaltaram a resistência desses trabalhadores quanto a tal processo em virtude de eles desenvolverem suas atividades de maneira individualizada, fazendo com que a ideia do trabalho coletivo ficasse desacreditada.

No que tange ao cadastro dos catadores de materiais recicláveis, percebeu-se que essa questão também apresenta baixo desempenho, uma vez que apenas Queimadas, mesmo que parcialmente, possuía o referido cadastro, que se encontrava instalado no lixão do citado município. No entanto, faltava o cadastro dos profissionais que realizavam suas atividades nas ruas da cidade. Logo, para que os municípios pesquisados obtivessem uma avaliação positiva para esse indicador, seria necessário um cadastro atualizado dos catadores de materiais.

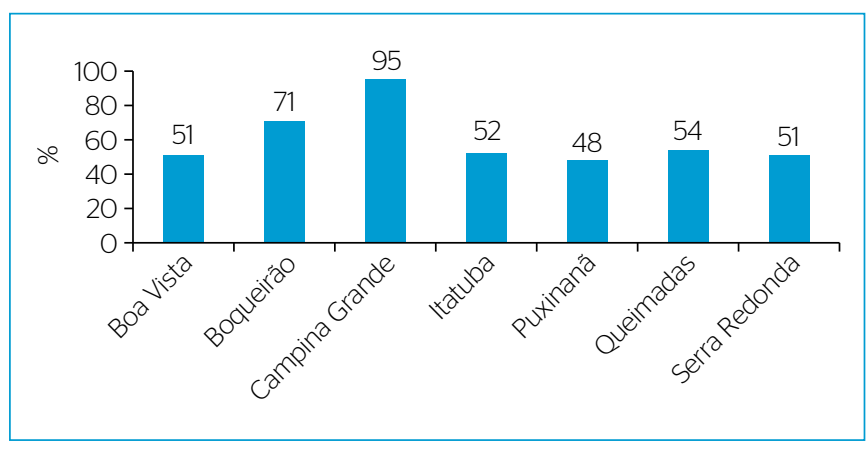

Figura 2 - Indicador 11: percentual de urbanização da população atendida pela coleta de resíduos. 
Em Campina Grande e Puxinanã existiam catadores de materiais recicláveis apenas nas ruas, o que é justificado pelo fato de as respectivas cidades não mais disporem seus resíduos em lixões, sendo tais materiais encaminhados para um aterro sanitário, local em que a entrada de catadores não é permitida. Em Itatuba, já se observa o inverso. Os catadores de materiais recicláveis estavam presentes apenas no ambiente do lixão, não realizando suas atividades nas ruas, conforme declarado durante a pesquisa de campo. Nos demais municípios, os catadores estão presentes tanto nas ruas como no lixão municipal.

\section{Dimensão técnico-operacional}

A Figura 3 apresenta dados referentes à taxa de cobertura do serviço de coleta dos RSU nos municípios pesquisados.

Apenas a cidade de Campina Grande, com base na Figura 3, apresenta taxa superior a 90\%; em seguida, aparece Boqueirão, com 72,8\%; e, com menor índice, a Itatuba. Sobre esse indicador, no caso da região estudada, cabe destacar o fato de que, fora Campina Grande, que exibe grande concentração populacional na área urbana, nos demais municípios ainda é muito marcante a presença de pessoas residindo na área rural do município, o que repercute diretamente nos dados levantados, visto que, na pesquisa de campo, se verificou que a coleta na zona rural, quando existe, é ineficiente, pois não cobre sua totalidade, assim como a frequência é irregular, acarrentando danos ambientais e à saúde pública da população rural.

A frequência da coleta dos RSU é realizada na quase totalidade da área residencial dos municípios pesquisados, em média, três vezes por semana. No que se refere ao centro comercial, normalmente essa coleta ocorre diariamente (exceto aos domingos), em virtude do grande volume de resíduos gerados pelos estabelecimentos do local.

Boqueirão, Campina Grande e Queimadas realizam a coleta residencial três vezes por semana e a comercial seis vezes na semana (de segunda-feira a sábado). Diferentemente dos municípios citados, Itatuba e Serra Redonda fazem a coleta dos RSU de segunda-feira a domingo (sete dias), tanto na área residencial quanto na comercial. Saindo um pouco dos dados apontados, encontram-se Boa Vista e

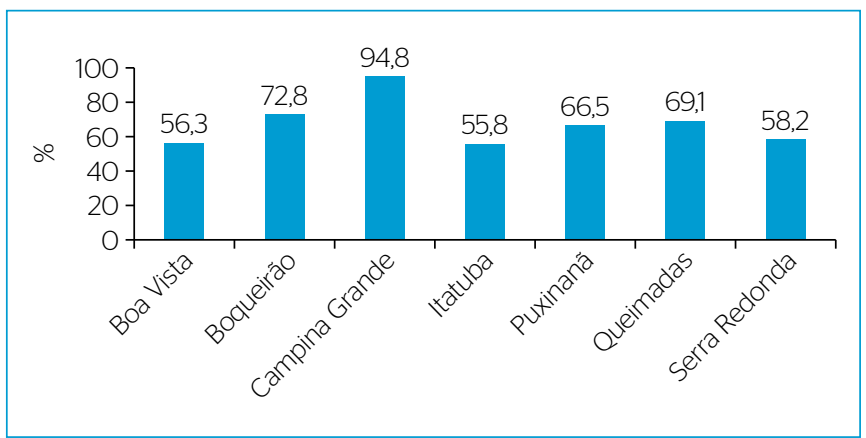

Figura 3 - Indicador 18: percentual de cobertura do serviço de coleta dos resíduos sólidos urbanos.
Puxinanã, nos quais a coleta se dá, na área residencial, respectivamente duas e três vezes por semana, enquanto a coleta comercial corresponde, em ambos os casos, à frequência de três vezes por semana.

Levando em consideração a importância da coleta e apoiados na literatura consultada (MONTEIRO, 2001; GUERRA, 2011), considerou-se que, quanto maior a frequência, menor será o acúmulo de resíduos em vias públicas e, por conseguinte, menores serão também os impactos negativos decorrentes da exposição dos RSU. Por se tratar de um estudo regional, a população apresenta níveis de consciência ambiental similares, justificando o critério utilizado de que há o entendimento de que cidade limpa é aquela que não se suja, o que pode ser percebido em cidades com um nível de consciência ambiental mais elevado, tais como as da Holanda, Dinamarca e Alemanha, por exemplo.

$O$ indicador quantidade de transportes utilizada na coleta dos RSU por mil habitantes permite avaliar a capacidade da frota de veículos e os equipamentos usados nos serviços de limpeza urbana. Para fins de normalização, caminhões compactadores ou não foram enquadrados no padrão de um caminhão com capacidade média de $8 \mathrm{~m}^{3}$ e sem compactação, ou seja, com capacidade para transportar 5 toneladas, em média, conforme a maioria dos transportes da região) Para análise desse indicador, tomaram-se como referência informações disponibilizados pela PNSB 2008 (IBGE, 2010b), como forma de obter dados mais seguros, haja vista que no momento da aplicação dos questionários com os gestores foram comuns dúvidas e inseguranças por parte deles na prestação de tais informações. A Figura 4 traz dados do indicador, levando em conta o cálculo estipulado para a sua obtenção (unidades/população urbana).

Considerando os dados da Figura 4, nota-se que o município que apresentou maior proporção transporte/população urbana foi Puxinanã, e os que possuíram menor proporção foram Queimadas e Itatuba.

Quanto à adequação dos transportes utilizados na coleta dos RSU, informa-se que a análise da frota de cada município foi ponderada por meio da caracterização dos transportes disponíveis para esse fim, com base na PNSB 2008 e nas observações realizadas in loco, nas quais foi possível identificar as condições em que os resíduos eram coletados e transportados para o local de disposição final.

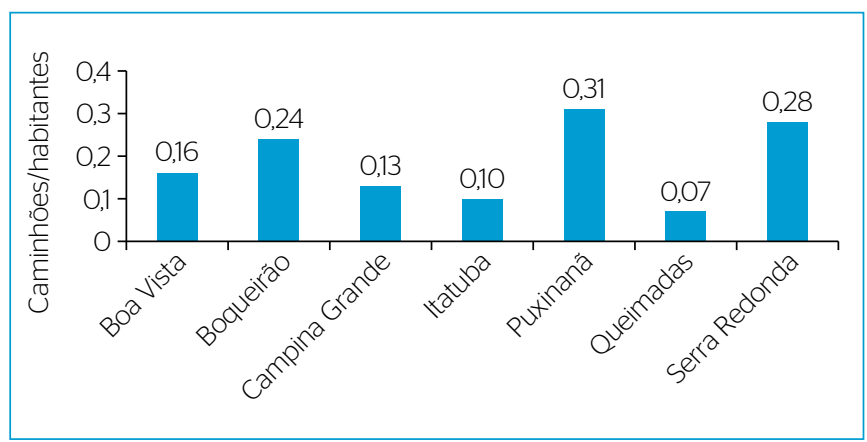

Figura 4 - Indicador 20: quantidade de transportes utilizada na coleta dos resíduos sólidos urbanos por mil habitantes. 
Para tanto, tomaram-se como referência as recomendações constantes da NBR 13221/2003 (ABNT, 2003), pela qual foi diagnosticado que a maioria dos municípios pesquisados (cinco, em um total de sete) utiliza veículos que não atendem ao estabelecido pela norma citada, uma vez que os resíduos são transportados em caminhões abertos, sem a devida proteção desses materiais, de modo a evitar que se espalhem pelas vias públicas.

Outro indicador avaliado foi a existência de ações fiscalizatórias relacionadas à gestão dos RSU promovidas pelo poder público municipal. Dos sete municípios pesquisados, três (Itatuba, Queimadas e Serra Redonda) alegaram não ter uma equipe de fiscalização. Desse modo, a atividade não realizada pela prefeitura. Os que informaram realizar esses serviços - Boa Vista, Boqueirão, Campina Grande e Puxinanã — foram avaliados positivamente.

O indicador existência do plano municipal de RSU é considerado importante, porque o documento estabelece normas e diretrizes para a gestão dos RSU no que se refere às especificidades locais, como forma de buscar a eficiência e a sustentabilidade da gestão. Com base na Lei $n^{\circ} 12.305 / 2010$, a elaboração desse plano é indispensável para os municípios.

O plano municipal de RSU não foi elaborado por quatro municípios avaliados: Boa Vista, Boqueirão, Itatuba e Serra Redonda. Somente Puxinanã informou possuir um plano de gestão, mas este, quando solicitado, não foi apresentado. Os demais, Campina Grande e Queimadas, alegaram que o referido plano se encontrava em fase de elaboração. Para fins de compreensão, informa-se que os municípios que não possuem o plano foram avaliados negativamente (0); os que alegaram que o plano se encontrava em elaboração tiveram uma avaliação considerada parcialmente adequada $(0,5)$, por acreditar-se que estão mais avançados em relação aos municípios que ainda necessitam realizar o seu planejamento; e o único que declarou ter o plano, como não o apresentou, também foi avaliado negativamente (0), haja vista o referido plano ser um documento público e que deve estar à disposição da população. Nesse caso, nenhum município foi avaliado positivamente, não obtendo a pontuação máxima para tal indicador $(1,0)$. Pelo exposto e para fins de análise do presente indicador, foi utilizada a seguinte escala de gradação: $(1,0)$ possui Plano Municipal de Gestão dos Resíduos Sólidos (PMGRS); (0,5) o PMGRS encontra-se em fase de elaboração e (0) não possui o PMGRS.

Ainda no que tange aos aspectos legais, mas levando em consideração o indicador existência de uma legislação específica para a GRSU no município, apenas Campina Grande respondeu positivamente ao indicador, sendo a problemática dos resíduos objeto de leis e requerimentos, além de estar presente no Código de Postura do município, conforme dados disponibilizados pela Secretaria de Obras e Serviços Urbanos. Os demais informaram não existir nada específico para a GRSU. Apenas Boqueirão declarou a existência de informações na legislação municipal, mas elas são referentes aos resíduos de construção e demolição.

Um ponto negativo observado foi o baixo percentual de municípios que viabilizam a capacitação dos funcionários envolvidos direta ou indiretamente com o manejo dos RSU e os serviços de limpeza urbana. Apenas Campina Grande e Puxinanã declararam oferecer cursos que buscam ampliar o conhecimento desses funcionários sobre o correto manuseio dos resíduos. Dessa forma, entende-se que, quanto maior a oferta de cursos de capacitação, maior o conhecimento adquirido, menores as chances de ocorrerem acidentes com as pessoas diretamente envolvidas no recolhimento e deposição de RSU e melhor a qualidade dos serviços prestados.

Constatou-se que na cidade de Campina Grande há o uso de fardamentos e EPIs, a exemplo de luvas e botas, o que caracteriza uma avaliação adequada (1). Boqueirão e Serra Redonda não demonstraram o uso de fardamento, tampouco de EPIs, repercutindo diretamente em uma avaliação negativa do indicador (0). Nos demais municipíos, a utilização de EPIs foi avaliada como parcialmente adequada, visto que os funcionários se encontravam, nas observações in loco, usando alguns dos referentes equipamentos de segurança, ou fardamento.

Para o indicador existência de informações sobre a GRSU sistematizadas e disponibilizadas para a população em meio digital, foram observados alguns sites das prefeituras pesquisadas, mas, afora Itatuba, no qual se verificaram informações acerca da problemática dos resíduos, não foi localizada nenhuma informação referente à questão dos RSU para os demais municípios no período de realização da pesquisa.

O indicador existência de um canal de reclamações para os usuários foi visto na maioria dos municípios e foi declarado inexistente apenas na prefeitura de Itatuba. Nas cidades que realizam esse serviço, o registro dá-se de maneira informal e diretamente com o responsável pela pasta, principalmente quando considerado o fato de que a maioria dos municípios pesquisados é de pequeno porte, o que favorece essa prática informal. Em Campina Grande, o registro ocorre por meio de reclamações diretas pelo telefone da Secretaria de Serviços Urbanos e Meio Ambiente, não havendo um número específico para esse fim.

Um ponto negativo foi que nenhum dos municípios tem controle sobre a quantidade de ocorrências de lançamentos de RSU em locais inadequados. Por esse motivo, foram recorrentes as afirmações de que "todas as solicitações de serviços são atendidas", à medida que são feitas ao responsável pela pasta. A ausência do controle formal das ocorrências impossibilita um acompanhamento maior das solicitações, de modo a se verificar a eficiência na prestação desse serviço, bem como os locais de maior incidência de registros, o que poderia auxiliar na gestão.

A avaliação do indicador porcentagem das escolas que desenvolvem programas de coleta seletiva demonstrou que somente três municípios contavam com escolas que desenvolviam alguma iniciativa no sentido conscientizar os alunos quanto à importância da adequada separação dos resíduos. O município que apresentou melhor desempenho foi Boa Vista, com $20 \%$ das escolas com programas de coleta seletiva; seguido por Queimadas, com 15,62\%; e Campina Grande, com $8,45 \%$. Dos demais municípios, apenas Boqueirão declarou que possuía 
projetos para ações de coleta seletiva nas escolas municipais (total de 32 escolas), mas eles ainda não se encontravam em desenvolvimento.

No que se refere ao desenvolvimento de campanhas voltadas para boas práticas de GRSU, quatro municípios (Boa Vista, Boqueirão, Campina Grande e Queimadas) informaram que desenvolviam ações nesse sentido. Os demais (Itatuba, Puxinanã e Serra Redonda) alegaram que não realizavam tais atividades. Observou-se que foi recorrente a afirmação de que ações de conscientização ambiental envolvendo a temática de resíduos, apesar de existirem, ainda não tinham efetividade.

Quanto à existência de conselhos municipais ou instâncias similares, apenas Campina Grande declarou possuir um conselho, o Conselho Municipal de Meio Ambiente (CODEMA), estando este em atividade.

\section{Dimensão econômico-financeira}

Tendo como base a pesquisa de campo realizada, foi recorrente a ausência de informações específicas sobre os gastos referentes ao manejo dos resíduos (varrição, coleta e transporte), o que impede uma análise mais detalhada e a otimização das despesas, sendo considerado um ponto negativo para a GRSU.

Em decorrência do não fornecimento de valores específicos pela grande maioria dos munícios pesquisados, recorreu-se ao Portal da Cidadania do Tribunal de Contas da Paraíba (Sagres/TCE) para levantamento do orçamento anual da secretaria, como forma de buscar a comparabilidade entre os municípios. A Figura 5 apresenta informações referentes à relação de gastos por habitante dos municípios pesquisados.

Para o indicador pagamento de pessoal encarregado pelo serviço de coleta e limpeza urbana, informa-se que esse dado foi calculado por estimativa, uma vez que apenas três municípios (Boa Vista, Boqueirão e Campina Grande), disponibilizaram informações para cálculo do indicador. Diante da inexistência ou recusa por parte dos gestores municipais em fornecer dados referentes ao número de funcionários envolvidos na GRSU, bem como os gastos referentes ao pagamento desse pessoal, recorreu-se a dados oficiais para obtenção de informações que auxiliassem na construção desse indicador. Registra-se que o

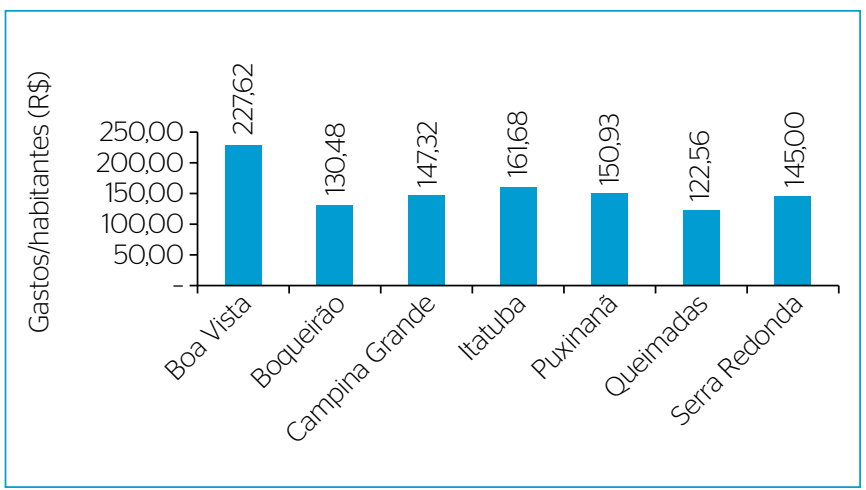

Figura 5 - Relação do orçamento anual da Secretaria de Obras e Serviços Urbanos pela população de cada município. município de Campina Grande, apesar de ter disponibilizado o valor referente ao pagamento de pessoal envolvido com o serviço de coleta e limpeza urbana, repassou dados do ano 2012 e que dizem respeito apenas ao pessoal terceirizado.

Para tanto, levou-se em consideração o número de funcionários informados pelo banco de dados da PNSB e o salário mínimo correspondente à época de realização da pesquisa para calcular o indicador (o valor do salário mínimo para o ano de 2013 era de $\mathrm{R} \$ 678,00$ - seiscentos e setenta e oito reais). A Figura 6 traz o resultado desse indicador para cada município.

Com base na Figura 6, o município de Boa Vista destacou-se por apresentar maior relação ( $\mathrm{R}$ /população urbana), quando comparado aos demais municípios. Na última posição apareceu Queimadas, com o menor índice para o indicador em questão.

Para o indicador recuperação de áreas degradadas com RSU (lixão), nenhum dos municípios da RMCG pesquisados declarou possuir despesas nesse sentido.

Passando a analisar dados referentes à arrecadação, verificou-se que, dos municípios participantes da pesquisa, apenas Boa Vista, Campina Grande e Queimadas declararam realizar cobranças dos serviços de coleta de resíduos e limpeza urbana aos usuários, e tais serviços foram avaliados positivamente, em detrimento dos municípios de Boqueirão, Itatuba, Puxinanã e Serra Redonda, que não possuem a cobrança da taxa pelos serviços de coleta de resíduos e limpeza urbana. Entende-se que a não cobrança pela execução dos serviços de limpeza urbana na RMCG acaba por fazer com que os municípios, principalmente os de pequeno porte, retirem essas despesas de receitas destinadas para outros fins, comprometendo não só a gestão dos RSU, mas toda a administração pública. Desse modo, considera-se como positivo apenas o fato de existir a cobrança. Ainda que ela não cubra totalmente os custos com a GRSU, já se porta como um avanço em relação às demais cidade, que não realizam nenhum tipo de cobrança.

Outra fonte de arrecadação refere-se ao FPM. Ele é, em alguns casos, o principal gerador de receita do município, o que ressalta a

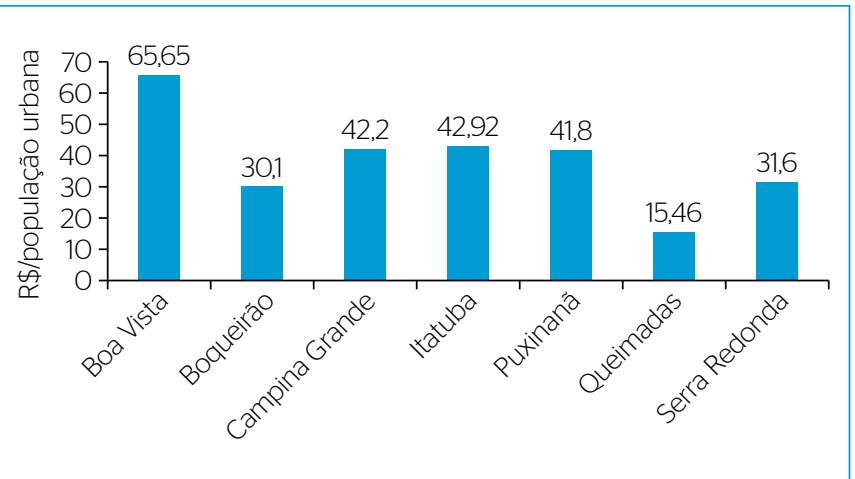

Figura 6 - Indicador 40: pagamento de pessoal encarregado pelo serviço de coleta e limpeza urbana. 
sua importância. Para o cálculo, optou-se por trabalhar com a população total, por entendermos que o FPM é uma receita destinada ao município. Observou-se que Boa Vista se destacou quanto a esse fundo com o montante de R\$661,73/habitante, seguido de Serra Redonda ( $\$$ \$ 584,48) e Itatuba ( $\$ 538,58)$. Em último, aparece Campina Grande ( $\$$ 133,02).

No que se refere ao indicador revenda de materiais recicláveis e do composto orgânico, registra-se que, em virtude de nenhum município pesquisado dispor de coleta seletiva, triagem e/ou compostagem, de acordo com a PNSB 2008 (IBGE, 2010b), a arrecadação se torna inexistente para esse tipo de atividade.

\section{CONSIDERAÇÕES FINAIS}

À luz dos dados descritos, observa-se que, de forma geral, os sete municípios da RMCG pesquisados são portadores de sérias deficiências na execução dos serviços referentes à GRSU em todas as dimensões investigadas. É bem verdade que alguns deles se destacam em virtude de exibirem maior número de indicadores considerados inadequados para a obtenção de uma gestão eficiente e sustentável, quando comparados aos demais. Logo, pode-se dizer que a GRSU nos pequenos municípios foi apresentada por seus gestores de maneira deficitária, uma vez que foi recorrente a ausência de informações sobre a execução da gestão, não estando estas estruturadas nem sistematizadas de modo a possibilitar o melhor desempenho do sistema.
De posse dos resultados, observou-se que a GRSU é extremamente carente no quesito disposição final, pois a maioria dos municípios pesquisados $(71,43 \%)$ deposita seus resíduos em vazadouros a céu aberto, os lixões. Assim, a implantação de aterros sanitários é fundamental para a eficácia da GIRSU, etapa que requer maiores investimentos em todo o processo.

No que se refere aos aspectos sociais, destaca-se a necessidade de inclusão social dos catadores de materiais recicláveis na GIRSU, perpassando essa inclusão por um processo de formalização da categoria, por meio da criação de cooperativas e associações. A falta de uma organização por parte dos catadores de materiais recicláveis reflete, conforme o levantamento realizado, diretamente na ausência de parcerias entre o poder público local e esses trabalhadores.

Outra questão bastante preocupante diz respeito aos aspectos econômico-financeiros, visto que poucos foram os gestores que demonstraram números comparativos entre a arrecadação e os gastos com o sistema de coleta, transporte e destinação de resíduos, o que compromete a autossustentabilidade (conforme a Lei no 12.305/2010) da GRSU, culminando, por conseguinte, na ineficiência da gestão.

Registra-se que o modelo se apresentou viável, uma vez que foi pautado na análise comparativa dos dados. Trabalhou-se com valores relativos, visando à comparabilidade entre os municípios participantes da pesquisa, elaborando uma radiografia da GRSU para cada município, a qual serve como ferramenta preciosa para os órgãos municipais competentes.

\section{REFERÊNCIAS}

AMORIN, V.P. (1996) Resíduos sólidos urbanos: o problema e a solução. Brasília: Roteiro Editorial.

ANDRADE, T.R.; SILVA, C.E. (2009) Análise de sustentabilidade na gestão de resíduos sólidos na cidade: o caso de Paripiranga, Bahia, Brasil. Revista Campus, Paripiranga, v. 2, n. 4, p. 78-105.

ASSOCIAÇÃO BRASILEIRA DE EMPRESAS DE LIMPEZA PÚBLICA E RESÍDUOS ESPECIAIS (ABRELPE). (2014) Panorama dos Resíduos Sólidos 2014. Disponível em: <http://www.abrelpe.org.br/ Panorama/panorama2014.pdf>. Acesso em: O3 abr. 2016.

ASSOCIAÇÃO BRASILEIRA DE NORMAS TÉCNICAS (ABNT). (2003) NBR 13221: Transporte terrestre de resíduos. Rio de Janeiro: ABNT.

BAASCH, S.S.N. (1995) Um sistema de suporte multicritério aplicado na gestão dos resíduos sólidos nos municípios catarinenses. Tese (Doutorado) - Programa de Pós-Graduação em Engenharia de Produção, Universidade Federal de Santa Catarina, Florianópolis. Disponível em: <http://repositorio.ufsc.br/xmlui/ handle/123456789/76262>. Acesso em: 10 fev. 2012.
BARDIN, L. (1979) Análise de conteúdo. Lisboa: Edições 70.

BRASIL. Ministério da Saúde. (2009) Departamento de Informática do Sistema Único de Saúde - DATASUS. Brasil. Disponível em: <http://www2.datasus.gov.br//index.php>. Acesso em: 15 out. 2012.

BRASIL, Governo Federal. Ministério das Cidades. Secretaria Nacional de Saneamento Ambiental. Sistema Nacional de Informações sobre Saneamento - SNIS/2011. Brasília, janeiro de 2012b. Disponível em: http://www.snis.gov.br/>. Acesso em: 30/04/2012.

Presidência da República. Casa Civil. (2010) Lei no 12.305, de 02 de agosto de 2010. Institui a Política Nacional de Resíduos Sólidos e dá ouras providências. Disponível em: <http://www planalto.gov.br/ccivil_03/_ato2007-2010/2010/lei//12305.htm> Acesso em: $\mathrm{O} 3$ out. 2010.

CASTRO, M.A.O.; SILVA, N.M.; MARCHAND, G.A.E.L. (2015) Desenvolvendo indicadores para a gestão sustentável de resíduos sólidos nos municípios de Iranduba, Manacapuru e Novo Airão, Amazonas, Brasil. Engenharia Sanitária Ambiental, v. 20, n. 3 p. 415-426. http://dx.doi.org/10.1590/S1413-41522015020000109837 
DANTAS, E.R.B. (2013) Análise do processo de implementação e operação do aterro sanitário no município de Puxinanã-PB utilizando o sistema de indicador de sustentabilidade pressãoestado-impacto-resposta (P-E-I-R). Dissertação (Mestrado) -. Programa de Pós-Graduação em Engenharia Civil e Ambiental, Universidade Federal de Campina Grande, Campina Grande.

DANTAS, K.M.C. (2008) Proposição e avaliação de sistemas de gestão ambiental integrada de resíduos sólidos através de indicadores em municípios do Estado do Rio de Janeiro. Tese (Doutorado) - Programa de Pós-Graduação de Engenharia, Universidade Federal do Rio de Janeiro, Rio de Janeiro.

GOMES, A.E.S.; ANDRADE, M.O. (2011) A gestão dos resíduos sólidos urbanos na Paraíba: parcerias entre setor público e terceiro setor. Gestão Pública: Práticas e Desafios, Recife, v. 2, n. 4, p. 206-227.

GUERRA, A.E. (2011) Qualidade e Eficiência dos Serviços de Saneamento. In: INSTITUTO BRASILEIRO DE GEOGRAFIA E ESTATÍSTICA. Atlas de Saneamento 2011. Brasília: MCidades. p. 28-46. Disponível em: <http://www.bge.gov.br/home/estatistica/populacao/ atlas_saneamento/default_zip.shtm>. Acesso em: 12 nov. 2011.

INSTITUTO BRASILEIRO DE GEOGRAFIA E ESTATÍSTICA (IBGE). Diretoria de Geociências. (2011) Atlas de Saneamento 2011. Rio de Janeiro: IBGE.

Ministério do Planejamento, Orçamento e Gestão. (2010a) Censo Demográfico 2010. Rio de Janeiro: IBGE.

Ministério do Planejamento, Orçamento e Gestão. (2010b) Pesquisa Nacional de Saneamento Básico - 2008. Rio de Janeiro: IBGE.

Sistema IBGE de Recuperação Automática (SIDRA). (2010c) Pesquisa Nacional por Amostra de Domicilios (PNAD-2010). Disponível em: <http://www.sidra.ibge.gov.br>. Acesso em: 12 nov. 2012.

JACOBI, P.; BESEN, G.R. (2006) Gestão de resíduos sólidos na Região Metropolitana de São Paulo: avanços e desafios. São Paulo em Perspectiva, São Paulo, Fundação Seade, v. 20, n. 2, p. 90-104.

JORNAL DO BRASIL. (2014) Senadores cobram apoio federal para fim dos lixões. Jornal do Brasil. Disponível em: <http://www.jb.com. br/pais/noticias/2014/01/23/senadores-cobram-apoio-federal-parafim-dos-lixoes/>. Acesso em: 23 jan. 2014.

MELO, L.A.; SAUTTER, K.D.; JANISSEK, P.R. (2009) Estudo de cenários para o gerenciamento dos resíduos sólidos urbanos de Curitiba. Engenharia Sanitária e Ambiental, Rio de Janeiro, v. 14, n. 4.

MILANEZ, B. (2002) Resíduos sólidos e sustentabilidade: princípios, indicadores e instrumentos de ação. 206f. Dissertação (Mestrado em Engenharia Urbana) - Universidade Federal de São Carlos, São Carlos.

MONTEIRO, J.H.P. (Org.). (2001) Manual de Gerenciamento Integrado de Resíduos Sólidos. Rio de Janeiro: IBAM. 204p.

MORAES, L.R.S. (2003) Gestão Integrada e Sustentável de Resíduos Sólidos Urbanos: um desafio para os municípios e a sociedade. Disponível em: <https://www.researchgate.net/
publication/237618751_GESTAO_INTEGRADA_E_SUSTENTAVEL_ DE_RESIDUOS_SOLIDOS_URBANOS_UM_DESAFIO_PARA_OS_ MUNICIPIOS_E_A_SOCIEDADE>. Acesso em: 21 mar. 2007.

MOTTA, R.S. (2006) Economia ambiental. Rio de Janeiro: Editora FGV. 228 p.

PARAÍBA. Governo do Estado da Paraíba. Agência Executiva de Gestão das Águas do Estado da Paraíba (AESA). GeoPortal Aesa. Mapa das Mesorregiões do Estado da Paraíba. Disponível em: <http://geo.aesa.pb.gov.br/>. Acesso em: 30 mar. 2012.

- Governo do Estado da Paraíba. Tribunal de Contas do Estado da Paraíba (TCE-PB). (2013) Portal da Cidadania (SAGRES). Dados referentes a receitas das prefeituras municipais alvos da pesquisa, entre os meses de janeiro a agosto de 2013.

POLAZ, C. N. M. Indicadores de sustentabilidade para gestão de resíduos sólidos urbanos. Dissertação (Mestrado) - Universidade Federal de São Carlos, 2009, 188 p.

POLAZ, C.N.M.; TEIXEIRA, B.A.N. (2007) Utilização de indicadores de sustentabilidade para a gestão de resíduos sólidos urbanos no município de São Carlos/SP. In: CONGRESSO BRASILEIRO DE ENGENHARIA SANITÁRIA E AMBIENTAL, 24., 2007, Belo Horizonte. Anais... Rio de Janeiro: ABES. CD-ROM.

RAMOS, R.R. (2013) Gestão de resíduos sólidos urbanos: indicadores de sustentabilidade aplicados a programas de gestão e associações de catadores de materiais recicláveis. Geografia, Londrina, v. 22, n. 3, p. 27-45.

SIENA, O. (2002) Método para avaliar progresso em direção ao desenvolvimento sustentável. Tese (Doutorado) - Programa de Pós-Graduação em Engenharia de Produção, Centro Tecnológico, Universidade Federal de Santa Catarina.

SILVA, C.L.; BASSI, N.S.S. (2012) Políticas públicas e desenvolvimento local. In: SILVA, C.L. (Org.). Políticas públicas e desenvolvimento local: instrumentos e proposições de análise para o Brasil. Petrópolis: Vozes.

SILVA, C. L.; FUGII, G.M.; BASSI, N.S.; SANTOYO, A.H. (2O15) O que é relevante para planejar e gerir resíduos sólidos? Uma proposta de definição de variáveis para a formulação e avaliação de políticas públicas. Revista Bibliográfica de Geografía y Ciencias Sociales, v. 20, ก. 1114.

SILVA, C.L.; FUGII, G.M.; SANTOYO, A.H.; BASSI, N.S.; VASCONCELOS, M.C. (2014) Gestão de resíduos sólidos urbanos em capitais brasileiras: alternativas para um modelo de gestão. Revista Brasileira de Ciências Ambientais, p. 118-131.

UGALDE, J.C. (2010) Aplicação de indicadores de sustentabilidade para avaliar a gestão de resíduos sólidos urbanos em Porto Velho/ RO. 135f. Dissertação (Mestrado em Desenvolvimento Regional) Núcleo de Ciências e Tecnologia, Programa de Pós-Graduação em Desenvolvimento Regional, Universidade Federal de Rondônia, Porto Velho, Rondônia. 
Anexo 1 - Informações correspondentes aos indicadores utilizados para cada município da Região Metropolitana de Campina Grande (RMCG) alvo da pesquisa.

\begin{tabular}{|c|c|c|c|c|c|c|c|c|c|}
\hline \multirow{2}{*}{ Indicador Variável } & \multirow{2}{*}{$\begin{array}{l}\text { Tipo de relação do } \\
\text { indicador e justificativa }\end{array}$} & \multirow{2}{*}{ Fórmula de cálculo } & \multicolumn{7}{|c|}{ Valores para cada município (relativos) } \\
\hline & & & BV & BO & CG & $\overline{I T}$ & $\mathrm{PU}$ & QU & SR \\
\hline $\begin{array}{l}\text { Quantidade de } \\
\text { RSU per capita }\end{array}$ & $\begin{array}{c}\text { Minimizar } \\
\text { Quanto menor a } \\
\text { quantidade de resíduo } \\
\text { gerada, menores } \\
\text { os impactos }\end{array}$ & $\begin{array}{l}\text { Quantidade } \\
\text { diária de resíduos } \\
\text { gerados } \times 1.000 \text { / } \\
\text { população urbana }\end{array}$ & $\begin{array}{c}1,2 \mathrm{~kg} / \\
\text { hab./dia }\end{array}$ & $\begin{array}{c}0,832 \mathrm{~kg} / \\
\text { hab./dia }\end{array}$ & $\begin{array}{l}1,23 \mathrm{~kg} / \\
\text { hab./dia }\end{array}$ & $\begin{array}{c}1,2 \mathrm{~kg} / \\
\text { hab./dia }\end{array}$ & $\begin{array}{c}1,4 \mathrm{~kg} / \\
\text { hab./dia }\end{array}$ & $\begin{array}{c}\text { 0,764 kg/ } \\
\text { hab./dia }\end{array}$ & $\begin{array}{c}1,6 \mathrm{~kg} / \\
\text { hab./dia }\end{array}$ \\
\hline $\begin{array}{l}\text { Coleta seletiva } \\
\text { e triagem }\end{array}$ & $\begin{array}{c}\text { Maximizar } \\
\text { Quanto maior a } \\
\text { população atendida, } \\
\text { menor a quantidade } \\
\text { de resíduos dispostos } \\
\text { inadequadamente }\end{array}$ & $\begin{array}{c}\text { Porcentagem } \\
\text { da população } \\
\text { urbana atendida } \\
\text { ou porcentagem } \\
\text { da área }\end{array}$ & Não & Não & Não & Não & Não & Não & Não \\
\hline $\begin{array}{l}\text { Formas de } \\
\text { disposição final } \\
\text { dos RSU (aterro } \\
\text { sanitário, aterro } \\
\text { controlado e } \\
\text { lixões) }\end{array}$ & $\begin{array}{c}\text { Maximizar (aterros) } \\
\text { A presença dessa } \\
\text { forma de disposição } \\
\text { minimiza os } \\
\text { impactos ambientais } \\
\text { decorrentes dos RSU } \\
\\
\text { Minimizar (lixões) } \\
\text { Considerada a forma } \\
\text { mais degradante de } \\
\text { disposição dos RSU }\end{array}$ & $\begin{array}{c}\text { Havendo uma } \\
\text { única forma de } \\
\text { disposição dos RSU } \\
\text { do município, em } \\
\text { caso de mais de } \\
\text { uma alternativa, } \\
\text { será calculada a \% } \\
\text { da área atendida } \\
\text { para esse tipo de } \\
\text { disposição }\end{array}$ & Lixão & Lixão & $\begin{array}{c}\text { Aterro } \\
\text { Sanitário }\end{array}$ & Lixão & $\begin{array}{l}\text { Aterro } \\
\text { Sanitário }\end{array}$ & Lixão & Lixão \\
\hline $\begin{array}{l}\text { Recuperação } \\
\text { de áreas de } \\
\text { lixões }\end{array}$ & $\begin{array}{c}\text { Maximizar } \\
\text { Quanto maior a } \\
\text { recuperação das áreas } \\
\text { dos antigos lixões, } \\
\text { menores os danos } \\
\text { ao ambiente. }\end{array}$ & $\begin{array}{l}\text { Informações } \\
\text { disponibilizadas } \\
\text { pelo gestor } \\
\text { municipal }\end{array}$ & Não & Não & Não & Não & Não & Não & Não \\
\hline $\begin{array}{l}\text { Fração da } \\
\text { população } \\
\text { urbana } \\
\text { atendida pela } \\
\text { coleta de } \\
\text { resíduos }\end{array}$ & $\begin{array}{c}\text { Maximizar } \\
\text { Quanto maior a } \\
\text { população municipal } \\
\text { atendida, maior a } \\
\text { eficiência da gestão } \\
\text { nesse setor (coleta) }\end{array}$ & $\begin{array}{l}\text { População atendida } \\
\text { / população total } \\
\text { do município }\end{array}$ & $100 \%$ & $100 \%$ & $100 \%$ & $90 \%$ & $100 \%$ & $100 \%$ & $100 \%$ \\
\hline $\begin{array}{l}\text { Existência } \\
\text { de catadores } \\
\text { de materiais } \\
\text { recicláveis }\end{array}$ & $\begin{array}{c}\text { Minimizar } \\
\text { Quanto menor } \\
\text { a presença de } \\
\text { catadores nas ruas, } \\
\text { menor a exposição } \\
\text { deles às condições } \\
\text { insalubres de trabalho }\end{array}$ & $\begin{array}{l}\text { Dados informados } \\
\text { pelo gestor } \\
\text { municipal ou } \\
\text { setor responsável, } \\
\text { podendo ainda } \\
\text { ser mensurados } \\
\text { indiretamente com } \\
\text { a observação de } \\
\text { catadores nas ruas }\end{array}$ & Sim & Sim & $\operatorname{Sim}$ & $\mathrm{Sim}$ & $\operatorname{Sim}$ & $\operatorname{Sim}$ & $\operatorname{Sim}$ \\
\hline $\begin{array}{l}\text { Formalização } \\
\text { da categoria de } \\
\text { catadores }\end{array}$ & $\begin{array}{c}\text { Maximizar } \\
\text { Quanto maior o } \\
\text { número de catadores } \\
\text { cooperados, maior } \\
\text { é o fortalecimento } \\
\text { da categoria }\end{array}$ & $\begin{array}{l}\text { Dados informados } \\
\text { pelo gestor } \\
\text { municipal ou } \\
\text { setor responsável } \\
\text { / número total de } \\
\text { catadores } \\
\end{array}$ & Não & Não & Sim & Não & Não & Não & Não \\
\hline $\begin{array}{l}\text { Cadastro de } \\
\text { catadores } \\
\text { de materiais } \\
\text { recicláveis }\end{array}$ & $\begin{array}{c}\text { Maximizar } \\
\text { Quanto maior o } \\
\text { número de parcerias, } \\
\text { maiores a inclusão } \\
\text { social dos catadores } \\
\text { e, consequente, } \\
\text { a valorização } \\
\text { da categoria }\end{array}$ & $\begin{array}{l}\text { Dados informados } \\
\text { pelo gestor } \\
\text { municipal ou setor } \\
\text { responsável }\end{array}$ & Não & Não & Não & Não & Não & $\operatorname{sim}$ & Não \\
\hline
\end{tabular}


Tabela 1 - Continuação.

\begin{tabular}{|c|c|c|c|c|c|c|c|c|c|}
\hline \multirow{2}{*}{ Indicador Variável } & \multirow{2}{*}{$\begin{array}{c}\text { Tipo de relação do } \\
\text { indicador e justificativa }\end{array}$} & \multirow{2}{*}{ Fórmula de cálculo } & \multicolumn{7}{|c|}{ Valores para cada município (relativos) } \\
\hline & & & BV & $\mathrm{BO}$ & CG & IT & PU & QU & SR \\
\hline $\begin{array}{l}\text { Taxa de } \\
\text { cobertura dos } \\
\text { serviços de } \\
\text { coleta dos RSU }\end{array}$ & $\begin{array}{c}\text { Maximizar } \\
\text { Quanto maior a } \\
\text { cobertura dos serviços } \\
\text { de coleta, maior a } \\
\text { população atendida e } \\
\text { menores os impactos }\end{array}$ & $\begin{array}{c}\text { Razão entre a } \\
\text { população atendida } \\
\text { com coleta } \\
\text { convencional sobre } \\
\text { população urbana } \\
\times 100\end{array}$ & $56,3 \%$ & $72,8 \%$ & $94,8 \%$ & $55,8 \%$ & $66,5 \%$ & $69,1 \%$ & $58,2 \%$ \\
\hline $\begin{array}{l}\text { Frequência da } \\
\text { coleta de RSU } \\
\text { (residencial-R/ } \\
\text { comercial-C) }\end{array}$ & $\begin{array}{c}\text { Maximizar } \\
\text { Quanto maior } \\
\text { a frequência da } \\
\text { coleta dos resíduos, } \\
\text { menor a exposição e } \\
\text { disposição deles no } \\
\text { meio ambiente }\end{array}$ & $\begin{array}{c}\text { Média ponderada: } \\
\text { somatória da } \\
\text { área atendida } \\
\text { × frequência / } \\
\text { somatório da área } \\
\text { total }\end{array}$ & $\begin{array}{c}\mathrm{R}-2 / \\
\mathrm{C}-3 \text { por } \\
\text { semana }\end{array}$ & $\begin{array}{c}\text { R-3 / } \\
\text { C-6 por } \\
\text { semana }\end{array}$ & $\begin{array}{c}\text { R-3/ } \\
\text { C-6 por } \\
\text { semana }\end{array}$ & $\begin{array}{c}\text { R-7 / } \\
\text { C-7 por } \\
\text { semana }\end{array}$ & $\begin{array}{c}\text { R-3 / } \\
\text { C-3 por } \\
\text { semana }\end{array}$ & $\begin{array}{c}\text { R-3/ } \\
\text { C-6 por } \\
\text { semana }\end{array}$ & $\begin{array}{c}\mathrm{R}-7 \text { / } \\
\text { C-7 por } \\
\text { semana }\end{array}$ \\
\hline $\begin{array}{l}\text { Quantidade } \\
\text { de transportes } \\
\text { utilizados na } \\
\text { coleta dos RSU } \\
\text { (per capita) }\end{array}$ & $\begin{array}{l}\text { Minimizar } \\
\text { Quanto menor } \\
\text { a quantidade de } \\
\text { transportes, menores } \\
\text { os custos com } \\
\text { manutenção e maior } \\
\text { a eficiência no que se } \\
\text { refere à sua utilização }\end{array}$ & $\begin{array}{l}\text { Informações } \\
\text { disponibilizadas } \\
\text { pelo gestor ou } \\
\text { responsável pelo } \\
\text { setor de limpeza } \\
\text { urbana }\end{array}$ & 0,19 & 0,24 & 0,13 & 0,10 & 0,31 & 0,07 & 0,28 \\
\hline $\begin{array}{l}\text { Adequação } \\
\text { dos transportes } \\
\text { utilizados na } \\
\text { coleta dos RSU }\end{array}$ & $\begin{array}{c}\text { Maximizar } \\
\text { Quanto maior a } \\
\text { adequação dos } \\
\text { transportes, maior a } \\
\text { eficiência dos serviços } \\
\text { prestados e menor } \\
\text { o risco de impactos } \\
\text { ambientais }\end{array}$ & $\begin{array}{c}\text { Observações } \\
\text { in loco nos } \\
\text { municípios, levando } \\
\text { em consideração } \\
\text { os veículos } \\
\text { disponibilizados } \\
\text { para o transporte } \\
\text { dos RSU e } \\
\text { a NBR 13221 } \\
\text { (BRASIL, 2003) }\end{array}$ & Não & Não & $\operatorname{Sim}$ & Não & Não & Sim & Não \\
\hline $\begin{array}{l}\text { Existência } \\
\text { de ações } \\
\text { fiscalizatórias }\end{array}$ & $\begin{array}{c}\text { Maximizar } \\
\text { Quanto maior o } \\
\text { número de ações } \\
\text { fiscalizatórias, maior } \\
\text { a eficiência dos } \\
\text { serviços prestados } \\
\text { à municipalidade e } \\
\text { menores os impactos } \\
\text { decorrentes da } \\
\text { gestão inadequada }\end{array}$ & $\begin{array}{l}\text { Informações } \\
\text { disponibilizadas } \\
\text { pelo setor } \\
\text { responsável pela } \\
\text { gestão dos RSU }\end{array}$ & Sim & $\operatorname{Sim}$ & $\operatorname{Sim}$ & Não & Não & Não & Não \\
\hline $\begin{array}{l}\text { Existência de } \\
\text { Plano Municipal } \\
\text { de RSU }\end{array}$ & $\begin{array}{c}\text { Maximizar } \\
\text { A existência de um } \\
\text { plano de gestão dos } \\
\text { RSU contribuirá para } \\
\text { a maior eficiência da } \\
\text { gestão, adequando-a } \\
\text { ao que é estabelecido } \\
\text { pela Lei no } 12.305 / 2010, \\
\text { devendo este estar } \\
\text { pronto para execução } \\
\text { até o mês de } \\
\text { agosto de } 2012\end{array}$ & $\begin{array}{l}\text { Informações } \\
\text { disponibilizados } \\
\text { pelo gestor } \\
\text { municipal ou setor } \\
\text { responsável pela } \\
\text { gestão dos RSU }\end{array}$ & Não & Não & $\begin{array}{l}\text { Fase de } \\
\text { elaboração }\end{array}$ & Não & Sim & $\begin{array}{l}\text { Fase de } \\
\text { elaboração }\end{array}$ & Não \\
\hline $\begin{array}{l}\text { Existência } \\
\text { de legislação } \\
\text { específica para } \\
\text { a gestão dos } \\
\text { RSU }\end{array}$ & $\begin{array}{c}\text { Maximizar } \\
\text { A existência de uma } \\
\text { legislação municipal } \\
\text { reflete numa tomada } \\
\text { de consciência do } \\
\text { poder público local } \\
\text { para com a gestão } \\
\text { dos RSU }\end{array}$ & $\begin{array}{l}\text { Informações } \\
\text { disponibilizadas } \\
\text { pelo gestor } \\
\text { municipal ou setor } \\
\text { responsável pela } \\
\text { gestão dos RSU }\end{array}$ & Não & Não & Sim & Não & Não & Não & Não \\
\hline
\end{tabular}


Tabela 1 - Continuação.

\begin{tabular}{|c|c|c|c|c|c|c|c|c|c|}
\hline \multirow{2}{*}{ Indicador Variável } & \multirow{2}{*}{$\begin{array}{l}\text { Tipo de relação do } \\
\text { indicador e justificativa }\end{array}$} & \multirow{2}{*}{ Fórmula de cálculo } & \multicolumn{7}{|c|}{ Valores para cada município (relativos) } \\
\hline & & & BV & $\mathrm{BO}$ & CG & IT & PU & QU & SR \\
\hline $\begin{array}{l}\text { Capacitação } \\
\text { dos } \\
\text { funcionários }\end{array}$ & $\begin{array}{c}\text { Maximizar } \\
\text { Quanto maior a oferta } \\
\text { de cursos, maior o } \\
\text { conhecimento relativo } \\
\text { à adequada gestão } \\
\text { dos RSU e melhor } \\
\text { a qualidade dos } \\
\text { serviços prestados }\end{array}$ & $\begin{array}{l}\text { Informações } \\
\text { disponibilizadas } \\
\text { pelo gestor } \\
\text { municipal ou setor } \\
\text { responsável pela } \\
\text { gestão dos RSU }\end{array}$ & Não & Não & Sim & Não & Sim & Não & Não \\
\hline $\begin{array}{l}\text { Utilização de } \\
\text { EPIs }\end{array}$ & $\begin{array}{c}\text { Maximizar } \\
\text { Quanto maior a } \\
\text { utilização de EPIs, } \\
\text { menor o risco de } \\
\text { acidentes decorrentes } \\
\text { da atividade realizada }\end{array}$ & $\begin{array}{l}\text { Informações } \\
\text { disponibilizadas } \\
\text { pelo setor } \\
\text { responsável e } \\
\text { por meio de } \\
\text { observações in } \\
\text { loco, sendo esse } \\
\text { uso avaliado em } \\
\text { três níveis (total, } \\
\text { parcial e sem uso) }\end{array}$ & Parcial & Não & Sim & Parcial & Parcial & Parcial & Não \\
\hline $\begin{array}{l}\text { Existência de } \\
\text { informações } \\
\text { sobre a gestão } \\
\text { dos RSU } \\
\text { sistematizadas } \\
\text { disponibilizadas } \\
\text { para a } \\
\text { população em } \\
\text { meio digital }\end{array}$ & $\begin{array}{c}\text { Maximizar } \\
\text { Quanto maior a } \\
\text { disponibilidade de } \\
\text { informações referentes } \\
\text { à gestão dos RSU } \\
\text { e sua consequente } \\
\text { divulgação, maior o } \\
\text { acesso da população } \\
\text { a tais informações } \\
\text { e maior o grau de } \\
\text { conhecimento }\end{array}$ & $\begin{array}{l}\text { Informações } \\
\text { disponibilizadas } \\
\text { pelo gestor } \\
\text { municipal ou setor } \\
\text { responsável pela } \\
\text { gestão dos RSU e } \\
\text { observação nos } \\
\text { sites das prefeituras }\end{array}$ & Não & Não & Não & Sim & Não & Não & Não \\
\hline $\begin{array}{l}\text { Porcentagem } \\
\text { de escolas que } \\
\text { desenvolvem } \\
\text { programas de } \\
\text { coleta seletiva }\end{array}$ & $\begin{array}{l}\text { Maximizar } \\
\text { Quanto maior } \\
\text { o número de } \\
\text { escolas envolvidas } \\
\text { nesses programas, } \\
\text { maior a taxa de } \\
\text { reaproveitamento de } \\
\text { resíduos e maior o } \\
\text { desenvolvimento da } \\
\text { consciência ambiental }\end{array}$ & $\begin{array}{c}\text { Informações } \\
\text { disponibilizadas } \\
\text { pelos gestores }\end{array}$ & $20 \%$ & O\% & $8,45 \%$ & О\% & O\% & $15,62 \%$ & ०\% \\
\hline $\begin{array}{l}\text { Existência de } \\
\text { campanha } \\
\text { voltada para } \\
\text { boas práticas } \\
\text { de GRSU }\end{array}$ & $\begin{array}{c}\text { Maximizar } \\
\text { Quanto maior o } \\
\text { número de campanhas } \\
\text { e a continuidade } \\
\text { delas, maiores a } \\
\text { sensibilização e } \\
\text { conscientização da } \\
\text { população para com } \\
\text { as causas ambientais }\end{array}$ & $\begin{array}{c}\text { Informações } \\
\text { disponibilizadas } \\
\text { pelos gestores }\end{array}$ & Sim & Sim & $\operatorname{Sim}$ & Não & Não & $\operatorname{Sim}$ & Não \\
\hline
\end{tabular}


Tabela 1 - Continuação.

\begin{tabular}{|c|c|c|c|c|c|c|c|c|c|}
\hline \multirow{2}{*}{ Indicador Variável } & \multirow{2}{*}{$\begin{array}{c}\text { Tipo de relação do } \\
\text { indicador e justificativa }\end{array}$} & \multirow{2}{*}{ Fórmula de cálculo } & \multicolumn{7}{|c|}{ Valores para cada município (relativos) } \\
\hline & & & BV & BO & CG & IT & PU & QU & SR \\
\hline $\begin{array}{l}\text { Existência de } \\
\text { conselhos } \\
\text { municipais } \\
\text { ou instâncias } \\
\text { similares }\end{array}$ & $\begin{array}{c}\text { Maximizar } \\
\text { A existência e } \\
\text { efetividade de } \\
\text { conselhos expressa a } \\
\text { eficiência do município } \\
\text { no que se refere a } \\
\text { ações de melhoria da } \\
\text { qualidade ambiental, } \\
\text { por meio de ações } \\
\text { em prol da adequada } \\
\text { gestão dos RSU }\end{array}$ & $\begin{array}{l}\text { Informações } \\
\text { disponibilizadas } \\
\text { pelos gestores }\end{array}$ & Não & Não & Sim & Não & Não & Não & Não \\
\hline $\begin{array}{l}\text { Pagamento } \\
\text { de pessoal } \\
\text { encarregado } \\
\text { pelo serviço de } \\
\text { coleta e limpeza } \\
\text { urbana }\end{array}$ & $\begin{array}{c}\text { Minimizar } \\
\text { O menor custo com } \\
\text { pagamento por } \\
\text { pessoal encarregado } \\
\text { em razão da } \\
\text { quantidade de } \\
\text { resíduos coletada } \\
\text { representa maior } \\
\text { eficiência dos custos } \\
\text { com a gestão }\end{array}$ & $\begin{array}{l}\text { Razão entre o valor } \\
\text { pago ao pessoal } \\
\text { encarregado / } \\
\text { população urbana }\end{array}$ & $\begin{array}{c}\mathrm{R} \$ 65,6 / \\
\text { população } \\
\text { urbana }\end{array}$ & $\begin{array}{c}\text { R\$ 30,1/ } \\
\text { população } \\
\text { urbana }\end{array}$ & $\begin{array}{c}\mathrm{R} \$ \text { 42,2/ } \\
\text { população } \\
\text { urbana }\end{array}$ & $\begin{array}{c}\mathrm{R} \$ 42,9 / \\
\text { população } \\
\text { urbana }\end{array}$ & $\begin{array}{c}\text { R\$ 41,8/ } \\
\text { população } \\
\text { urbana }\end{array}$ & $\begin{array}{l}\mathrm{R} \$ 15,4 / \\
\text { população } \\
\text { urbana }\end{array}$ & $\begin{array}{c}\text { R\$ 31,6/ } \\
\text { população } \\
\text { urbana }\end{array}$ \\
\hline $\begin{array}{l}\text { Recuperação } \\
\text { de áreas } \\
\text { degradadas } \\
\text { com RSU }\end{array}$ & $\begin{array}{c}\text { Maximizar } \\
\text { A recuperação de } \\
\text { áreas degradadas } \\
\text { por RSU repercute } \\
\text { em melhorias nas } \\
\text { condições sanitárias } \\
\text { e ambientais, o que } \\
\text { reflete diretamente na } \\
\text { melhoria da qualidade } \\
\text { de vida da população }\end{array}$ & $\begin{array}{l}\text { Razão entre o valor } \\
\text { destinado para } \\
\text { recuperação de } \\
\text { áreas degradadas } \\
\text { pela quantidade de } \\
\text { resíduos coletadas }\end{array}$ & Não & Não & Não & Não & Não & Não & Não \\
\hline $\begin{array}{l}\text { Cobrança } \\
\text { dos serviços } \\
\text { de coleta de } \\
\text { resíduos e } \\
\text { limpeza urbana }\end{array}$ & $\begin{array}{c}\text { Maximizar } \\
\text { A existência de uma } \\
\text { taxa de cobrança pelos } \\
\text { serviços de gestão dos } \\
\text { resíduos reflete em } \\
\text { maiores investimentos } \\
\text { no setor e melhor } \\
\text { atendimento por parte } \\
\text { da população }\end{array}$ & $\begin{array}{l}\text { Informações } \\
\text { disponibilizadas } \\
\text { pelos gestores }\end{array}$ & Sim & Não & $\operatorname{Sim}$ & Não & Não & Sim & Não \\
\hline FPM & $\begin{array}{c}\text { Maximizar } \\
\text { Quanto maiores os } \\
\text { custos destinados à } \\
\text { gestão dos resíduos, } \\
\text { maiores tendem } \\
\text { a ser a eficiência } \\
\text { e a qualidade dos } \\
\text { serviços prestados }\end{array}$ & $\begin{array}{c}\text { Razão entre o } \\
\text { valor total do FPM } \\
\text { e o número total } \\
\text { de habitantes do } \\
\text { município }\end{array}$ & $\begin{array}{l}\mathrm{R} \$ 661,73 / \\
\text { habitante }\end{array}$ & $\begin{array}{c}\mathrm{R} \$ 487,99 / \\
\text { habitante }\end{array}$ & $\begin{array}{l}\mathrm{R} \$ 133,02 / \\
\text { habitante }\end{array}$ & $\begin{array}{c}\mathrm{R} \$ 538,58 / \\
\text { habitante }\end{array}$ & $\begin{array}{l}\mathrm{R} \$ 425,15 / \\
\text { habitante }\end{array}$ & $\begin{array}{l}\mathrm{R} \$ 301,14 / \\
\text { habitante }\end{array}$ & $\begin{array}{c}\mathrm{R} \$ 584,48 / \\
\text { habitante }\end{array}$ \\
\hline $\begin{array}{l}\text { Revenda de } \\
\text { materiais } \\
\text { recicláveis } \\
\text { e composto } \\
\text { orgânico }\end{array}$ & $\begin{array}{c}\text { Maximizar } \\
\text { Quanto maior } \\
\text { a arrecadação } \\
\text { decorrente do } \\
\text { reaproveitamento dos } \\
\text { RSU, maior a inclusão } \\
\text { social dos catadores } \\
\text { por meio da coleta } \\
\text { seletiva e menor a } \\
\text { disposição dos RSU no } \\
\text { meio ambiente } \\
\end{array}$ & $\begin{array}{l}\text { Razão entre o } \\
\text { valor total da } \\
\text { revenda do } \\
\text { material pela } \\
\text { quantidade } \\
\text { de quilos }\end{array}$ & Não & Não & Não & Não & Não & Não & Não \\
\hline
\end{tabular}

RSU: resíduos sólidos urbanos; BV: Boa Vista; BO: Boqueirão; CG: Campina Grande; IT: Itatuba; PU: Puxinanã; QU: Queimadas; SR: Serra Redonda; hab: habitante; EPI: equipamento de proteção individual; GRSU: gestão de resíduos sólidos urbanos; FPM: Fundo de Participação Municipal. 